\title{
EFFECTS OF COLOR TEMPERATURE OF LED LIGHTING ON ELECTROENCEPH-ALOGRAM (EEG) DURING ROBOT PROGRAMMING ACTIVITY: FOCUS ON STABILITY, CONCENTRATION, ACTIVATION, AND STRESS INDICES
}

\author{
Sungae Kim ${ }^{1}$ and Soon-Duk Jee ${ }^{2 *}$ \\ ${ }^{1}$ Woonam Middle School \\ ${ }^{2} J o n g c h o n$ Middle School \\ *duk1676@daum.net
}

\begin{abstract}
The purpose of the present study was to analyze the effects of LED lighting with three different color temperature values on the stability, concentration, activation, and stress indices of electroencephalogram (EEG) during a robot programming activity. The EEG was measured in the presence and absence of LED lighting. Variations in EEG from bilateral prefrontal and occipital lobes were measured during a robot programming activity under color temperature values in the presence of LED lighting. Based on the measured EEG values, the stability, concentration, activation, and stress indices were calculated and analyzed. Subjects were classified into two groups based on the brain regions from which a stronger $\alpha$ wave was generated (prefrontal or occipital lobes). LED lighting with a color temperature of $7000 \mathrm{~K}$ increased overall EEG indices during the robot programming activity; LED lighting with color temperature of $5000 \mathrm{~K}$ also increased several indices. These findings support previous results that high color temperatures over $5000 \mathrm{~K}$ may facilitate learning in mathematics and sciences, suggesting that color temperature may need to be adjusted according to the types of learning and personal characteristics of learners.
\end{abstract}

Keywords - EEG, robot programming activity, LED lighting, color temperature, stability index, concentration index, activation index, stress index

\section{INTRODUCTION}

Light enables humans to recognize objects and make judgments, and can therefore affect physical and mental health. With the transition of human activities from outdoor to indoor spaces, increasing emphasis is being placed on lighting in indoor environments. To cope with the environmental pollution caused by fluorescent lamps and the depletion of natural resources for energy production, light-emitting diode (LED) lighting, which has a high energy efficiency and is easily controllable, has been developed. LED lighting has been introduced not just to industrial sites but also to homes, as consumers are becoming more cognizant of environmental sustainability.

Lighting is related to eye strain and mental fatigue, and has a critical effect on learning. Good lighting for learning activities improves learning efficiency by providing the

Received: December 29, 2018

Reviewed: February 25, 2019

Accepted: March 5, 2019

* Corresponding Author 
environment needed for learning, providing students with emotional and psychological stability, reducing eye strain, preventing near-sightedness, and elevating concentration.[1] Due to the importance of lighting, there has been extensive research on LED lighting which demonstrates that various color temperature values of LED lighting are related with learning performance, con-centration, visual discrimination, and learning effects.[2]

Most studies analyzing the effect of LED lighting color temperature have focused on psychological aspects based on subjective evaluations. As such, more objective evaluations of psychological aspects are required. [3] Among the objective methods of analysis, electroencephalography (EEG) is a method that can objectively analyze brain functions by excluding social and cultural effects [4].

Brain research has been conducted extensively for the treatment of diseases such as depression and dementia; as well as in health domains such as education and sports. [5-8] The emotions induced by various visual stimuli may be measured through the variations in EEG frequency [9]. However, few studies have examined the correlation between LED lighting and learning performance using EEG, and the effects of LED lighting on educational activities are unclear.

Previous studies based on subjective evaluation have examined the effects of indoor temperature on concentration and the increase in preference and satisfaction depending on color temperature and illumination of LED lighting. [10][11] In contrast to general indoor environments, educational facilities which are related to learning, may involve various other parameters. Hence, verifying the correlation between educational facilities and LED lighting is critical. Moreover, since various types of education are provided in educational facilities, the correlations between the types of education and LED lighting should also be identified. Subjective evaluation of the effects of LED lighting on learning have been conducted, but studies in relation to specific learning activities are lacking.

While LED lighting is extensively installed in educational facilities at present, there is a need for more extensive systematic analyses of human psychological and physiological characteristics depending on the optical properties of LED lighting for specific learning activities. There is also a need for systematic research on methodologies to help students fully utilize their brain capacity for information processing, memory, and con-centration, by adjusting LED lighting to optimal conditions for performance. Compared to conventional questionnaire-based methods, EEG is a more systematic, scientific, and advanced technique for measuring the effects of LED lighting [12].

In the present study, a specific learning activity was chosen to investigate the correlation between LED lighting and learning. The chosen learning activity was a robot programming activity, which is an area of software education that is now emphasized as a necessary educational activity in preparation for the Fourth Industrial Revolution. [13]

In programming education, the difficulties involved in the learning of a programming language itself prevent the learners from developing interest and motivation, even before accomplishing the fundamental goal of the programming education, which is the improvement of problem-solving capability. Hence, a robot is often employed to address the problem of programming education. Positive results have been acquired in arousing interest, motivation, increasing participation and accomplishment, and improving creative problem-solving capabilities [14-17]. Given these positive effects, robots are recognized as appropriate tools for science, technology, engineering, and mathematics (STEM) and science, technology, engineering, art, and mathematics (STEAM) education. Indeed, educational applications and research on robots are expanding [18-20].

In a recently revised curriculum, the UK included advanced technology represented by robots [21-22]. Robot-related private education has recently become very popular in China.[23] Korea has also introduced robot-associated education in the recent-ly revised curriculum for elementary school education.[24]

Robot technology is one of the new core technologies to lead the Fourth Industrial Revolution, in which many countries are interested. For example, Korea, US, and China 
have announced a series of policies related to robots to promote development in industry and education. Research and Markets, the world's big-gest market research company, predicts that the market for educational robots will grow to a size of 1.6 billion USD in 2023 [25].

Therefore, we selected programming education for the operation of robots as a learning activity to validate the effects of LED light on EEG while engaged in a specific learning activity. The dependence of EEG on the color temperature of LED lighting was investigated by measuring the stability, activation, con-centration, and stress indices of EEG; these parameters are related to learning activities. Subjects were classified into two groups according to the brain regions from which a stronger alpha $(\alpha)$-wave was generated (prefrontal lobe or occipital lobe groups), wherein the $\alpha$-wave is related to the relief of stress and improvement of concentration[26]. The differences in stability, activation, concentration, and stress indices of EEG were analyzed between the two groups by varying the color temperatures of LED lighting.

\section{EXPERIMENTAL METHODS}

The lighting used in the experiment was SC0312CXN LED lighting manufactured by the "L" company (Korea). The LED lighting was designed to replace existing fluorescence lamps and has been applied to many educational facilities, including elementary, middle, and high schools; and universities. In the pre-sent study, considering the optical properties and controllable color temperatures of LED lighting used in the experiments, robot programming education was given at three different color temperature values $(3000 \mathrm{~K}, 5000 \mathrm{~K}$, and $7000 \mathrm{~K})$. While the subjects were performing robot programming, EEG was measured. Variation in EEG frequencies was analyzed based on EEG characteristics.

The optical properties of the lighting were measured using LMS-3M equipment ('O' Company, Korea) available in the Korea Photonic Technology Institute. Table I shows the optical properties of the LED lighting.

Table I. Chromaticity coordinates and color temperatures of lighting

\begin{tabular}{c|c|c|c|c|c|c}
\hline \multirow{2}{*}{$\begin{array}{c}\text { LED } \\
\text { Lighting }\end{array}$} & $\begin{array}{c}\text { Color } \\
\text { Temperature } \\
{[\mathrm{K}]}\end{array}$ & \multicolumn{2}{|c|}{$\begin{array}{c}\text { Chromaticity } \\
\text { Coordinates }\end{array}$} & \multicolumn{2}{c|}{ Rendering Index $\left(\mathrm{R}_{\mathrm{n}}\right)$} & \multirow{2}{*}{$\begin{array}{c}\text { Luminous Flux } \\
{[\mathrm{lm}]}\end{array}$} \\
\cline { 3 - 6 } & & $\mathrm{x}$ & $\mathrm{Y}$ & $\mathrm{R}_{1-8}$ & $\mathrm{R}_{1-15}$ & \\
\hline 1 & 3000 & 0.40 & 0.37 & 80 & 75 & 3,820 \\
2 & 5000 & 0.35 & 0.34 & 82 & 76 & 3,800 \\
3 & 7000 & 0.31 & 0.32 & 80 & 74 & 3,750 \\
\hline
\end{tabular}

The software program used as a tool for the robot programming activity was based on a graphic-based language that is easy to learn and allows realization of an algorithm through simple mouse manipulations. The robot employed in the present study was LEGO MINDSTORM EV3.

EEG was measured in a $30[\mathrm{~mm} 3]$-wide measurement room located in the Korea Research Institute of Chemical Technology, wherein LED lighting of different color temperatures could be varied and was installed in the sealed measurement room. The noise level was below $30[\mathrm{~dB}]$ in the soundproof and thermo-static measurement room. The illumination on the surface of the test desk was $500 \pm 50[1 \mathrm{x}]$.

The equipment used for EEG measurement was MP150 (BI-OPAC). Two types of caps (ECI Electro-Cap, Electro-Cap), large and small, prepared according to the international standards of "10-20 electrode system" exclusively for EEG, were employed. Surface electrodes were used. Highly conductive Electro-Gel was injected using a syringe to the electrodes attached to the EEG caps. 
According to the international standards of "10-20 electrode system," the EEG electrodes were attached to eight positions on the prefrontal lobes, frontal lobes, center, and occipital lobes. A reference electrode was attached behind the right earlobe, and the ground electrode behind the left earlobe.

Only the data obtained from the prefrontal and occipital lobes, directly affected by the LED lighting and robot programming activity, were used in the analysis. Electrooculogram (EOG, eye blinking information) was measured to remove the noise caused by eyeball movements. [27]

Subjects were 13 undergraduate students and 12 graduate students who were males between 19 and 35 years old, with no history of encephalopathy. From 12 hours before the experiment, the subjects were requested to avoid coffee, cigarettes, medicines, and alcohol, to avoid affecting the autonomic nervous system and sensibility. Before participating, subjects were given detailed explanations of the method of measuring the biological signals. For subjects who were new to the robot programming activity, 3 hours of fundamental education about robot programming were provided.

Subjects were instructed to perform the robot programming activity under three color temperature conditions $(3000 \mathrm{~K}, 5000 \mathrm{~K}$, and $7000 \mathrm{~K})$ during which their EEG was measured. Table II shows the methods and procedures involved in each experimental stage.

Table II. Experimental procedure

\begin{tabular}{|c|c|c|c|}
\hline Order & $\begin{array}{c}\text { Color } \\
\text { Temperature } \\
{[\mathrm{K}]}\end{array}$ & $\begin{array}{l}\text { Time } \\
(\mathrm{sec})\end{array}$ & Experimental Procedure \\
\hline 1 & $\begin{array}{c}0 \\
\text { (Natural Light) }\end{array}$ & 1800 & Attaching electrode and preparation \\
\hline \multirow[t]{2}{*}{2} & 3000 & 600 & Adaptation to experimental conditions \\
\hline & \multirow{4}{*}{3000} & 300 & Rest in comfort status \\
\hline \multirow{3}{*}{3} & & 600 & $\begin{array}{l}\text { Robot programming } \\
\text { (mental arithmetic) }\end{array}$ \\
\hline & & 300 & Rest in comfort status \\
\hline & & 600 & $\begin{array}{l}\text { Robot programming } \\
\text { (mental arithmetic) }\end{array}$ \\
\hline \multirow[t]{2}{*}{4} & \multirow[t]{2}{*}{5000} & 600 & Adaptation to experimental conditions \\
\hline & & 300 & Rest in comfort status \\
\hline \multirow{3}{*}{5} & \multirow{3}{*}{5000} & 600 & $\begin{array}{l}\text { Robot programming } \\
\text { (mental arithmetic) }\end{array}$ \\
\hline & & 300 & Rest in comfort status \\
\hline & & 600 & $\begin{array}{l}\text { Robot programming } \\
\text { (mental arithmetic) }\end{array}$ \\
\hline \multirow[t]{2}{*}{6} & 7000 & 600 & Adaptation to experimental conditions \\
\hline & \multirow{4}{*}{7000} & 300 & Rest in comfort status \\
\hline \multirow{3}{*}{7} & & 600 & $\begin{array}{l}\text { Robot programming } \\
\text { (mental arithmetic) }\end{array}$ \\
\hline & & 300 & Rest in comfort status \\
\hline & & 600 & $\begin{array}{l}\text { Robot programming } \\
\text { (mental arithmetic) }\end{array}$ \\
\hline
\end{tabular}

The EEG measured during the robot programming activity was converted to EEG indices considered as learning-related factors: (1) stability index, (2) activation index, (3) concentration index, and (4) stress index.

Definition 2.1: This is a definition of stability 
(2)

Definition 2.2: This is a definition of activity index

(3)

Definition 2.3: This is a definition of concentration index

(4)

Definition 2.4: This is a definition of stress index

The subjects were classified into two groups according to the brain region from which a stronger $\alpha$-wave was generated in the absence of lighting (prefrontal lobe and occipital lobe groups). Differences in stability, activation, and concentration indices between EEGs of the two groups were analyzed. (The t-test and Scheffe's test were used to analyze the difference in stability, activation, and concentration index between the two groups of EEGs.)

The EEG was analyzed using the Acq Knowledge 4.2 software program for MP150 (BIOPAC). Analysis of EEG obtained during the robot programming activity in the absence of lighting and under three different color temperature conditions of LED lighting is described below.

\section{RESULT}

\subsection{STABILITY INDEX DURING ROBOT PROGRAMMING UN-DER LED LIGHTING}

To investigate the stability index during robot programming according to color temperature, absolute $\alpha$-waves generated from the left and right brain during robot programming under three different LED color temperature conditions $(3000 \mathrm{~K}, 5000 \mathrm{~K}$, and $7000 \mathrm{~K}$ ) were measured. Asymmetry scores of absolute $\alpha$-waves were compared. The $\alpha$-wave is a basic stability wave that occurs when the mind and body are at ease, and represents the stable state of the brain. Fig 1 and Table III show the variation of the asymmetry scores of absolute $\alpha$-waves according to color temperature.

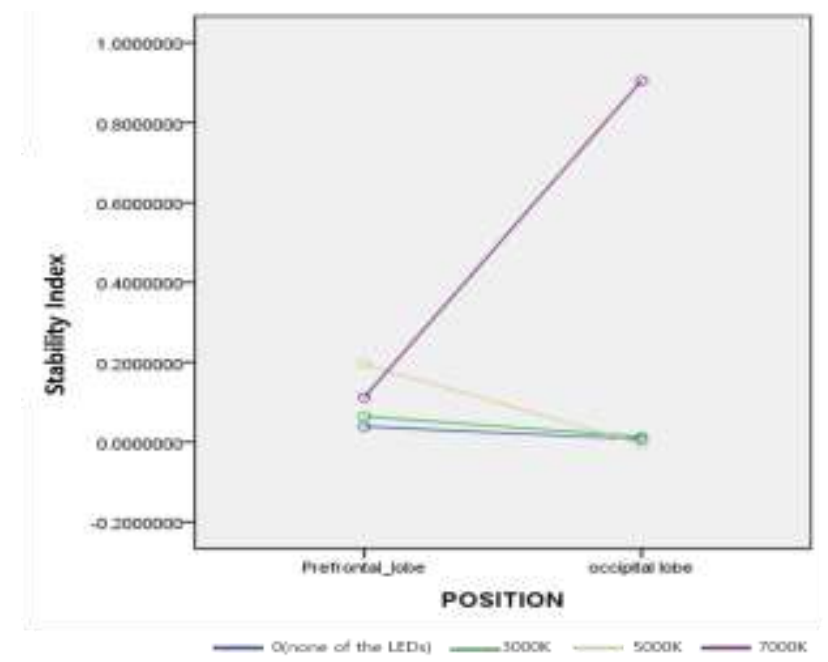

Fig. 1 The stability indices of brain positions during robot programming under LED lighting. The EEG was measured in the presence of LED light-ing with different color temperatures $(3000 \mathrm{~K}, 5000 \mathrm{~K}, 7000 \mathrm{~K})$ and absence of LED lighting. 
Table III. Stability indices according to brain position and color tempera-ture

\begin{tabular}{c|c|c|c|c}
\hline \multicolumn{2}{c|}{ Variable } & M & SD & N \\
\cline { 1 - 2 } Group & Color Temperature $[\mathrm{K}]$ & & .2509386870 & 25 \\
& 0 & .039289046 & .0567465195 & 25 \\
Prefrontal & 3000 & .064539263 & .3112641564 & 25 \\
lobe & 5000 & .194865727 & .1914201512 & 25 \\
& 7000 & .112119513 & .5099434071 & 25 \\
Occipital & 0 & .007529012 & .5157952662 & 25 \\
lobe & 3000 & .013697358 & .5354026384 & 25 \\
& 5000 & -.004815273 & .4007198109 & 25 \\
\hline
\end{tabular}

Scheffe's test revealed that the stability index of the brain position was significantly different at $7000 \mathrm{~K}(\mathrm{P}<0.05)$. Table IV shows the result of the Scheffe's test.

Table IV. Scheffe's test of stability index $(* \mathrm{P}<0.05)$

\begin{tabular}{c|c|c|c|c}
\hline \multicolumn{2}{c|}{ Color-Temperature[K] } & M & SD & Sig. \\
\hline \multicolumn{1}{c|}{$(\mathrm{I})$} & $(\mathrm{J})$ & & .0902556873 & .999 \\
0 & 3000 & -.015709281 & .0902556873 & .889 \\
0 & 5000 & -.071616198 & .0902556873 & $.000^{*}$ \\
3000 & 7000 & $-.485425164^{*}$ & .0902556873 & .999 \\
3000 & 0 & .015709281 & .0902556873 & .943 \\
3000 & 5000 & -.055906917 & .0902556873 & $.000^{*}$ \\
5000 & 7000 & $-.469715883^{*}$ & .0902556873 & .889 \\
5000 & 0 & .071616198 & .0902556873 & .943 \\
5000 & 3000 & .055906917 & .0902556873 & $.000^{*}$ \\
7000 & 7000 & $-.413808966^{*}$ & .0902556873 & $.000^{*}$ \\
7000 & 0 & $.485425164^{*}$ & .0902556873 & $.000^{*}$ \\
7000 & 3000 & $.469715883^{*}$ & .0902556873 & $.000^{*}$ \\
\hline
\end{tabular}

During the robot programming activity, the asymmetry score of the left and right brain was closest to 0 (zero) at $5000 \mathrm{~K}$ at the occipital lobes. This suggests that the subjects may have achieved emotional stability during the robot programming activity, as the balance of $\alpha$-waves between the left and right brain was increased. This suggests that stability during the robot programming activity was greatest at $5000 \mathrm{~K}$.

Absolute $\alpha$-wave dependence on color temperature revealed that the absolute $\alpha$-wave was generally strongest at $7000 \mathrm{~K}$ at the prefrontal and occipital lobes. When compared with that of the other color temperature values, the EEG stability index at $7000 \mathrm{~K}$ was significantly higher suggesting that $\alpha$-wave activation was greatest at $7000 \mathrm{~K}$ during the robot programming activity. The $\alpha$-wave is generated at rest during a state of comfort, indicating harmony between the body and the mind. Our results suggest that during the robot programming activity, the subjects felt most at ease at $7000 \mathrm{~K}$.

The difference in stability index of prefrontal and occipital lobe groups was analyzed (Fig 2 and Table V). The stability index was high at $7000 \mathrm{~K}$ in both groups. In addition, the change in stability index from the condition without LED lighting was greater at $7000 \mathrm{~K}$. The EEG stability index was significantly different between the two groups in the absence of LED lighting, with the exception of the prefrontal lobe group at $3000 \mathrm{~K}$. In the 
occipital lobe group, the effect of color temperature was minimal; a larger effect was observed at $7000 \mathrm{~K}$.

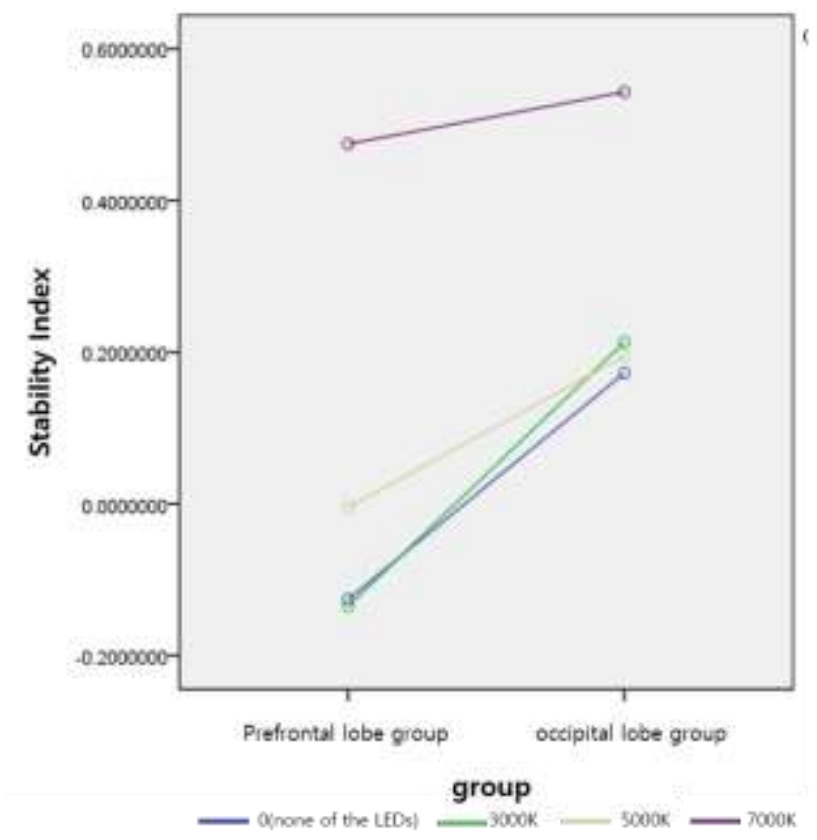

Fig. 2 Stability indices of the two groups during robot programming under LED lighting with three types of color temperature. Subjects were classified into two groups according to the brain regio from which a stronger alpha $(\alpha)$-wave was generated.

Table V. Stability indices according to groups and color temperatures

\begin{tabular}{c|c|c|c|c}
\hline \multicolumn{2}{c|}{ Variable } & M & SD & N \\
\cline { 1 - 2 } Group & Color Temperature $[\mathrm{K}]$ & & .4043961416 & 52 \\
Prefrontal & 0 & -.125675079 & .3299241971 & 52 \\
group & 3000 & -.135211977 & .4894515817 & 52 \\
& 5000 & -.004609409 & .5454101274 & 52 \\
& 7000 & .474491770 & .3360703892 & 48 \\
Occipital & 0 & .172493138 & .3121312367 & 48 \\
group & 3000 & .213448597 & .3795595736 & 48 \\
& 5000 & .194659863 & .4801342987 & 48 \\
\hline
\end{tabular}

Scheffe's test revealed that the stability index was significantly different between the two groups at $7000 \mathrm{~K}(\mathrm{P}<0.05)$. Table 5 shows the post-hoc results.

\subsection{ACTIVATION INDEX DURING ROBOT PROGRAMMING UN-DER LED LIGHTING}

The sensorimotor rhythm (SMR) and low-beta $(\beta)$ waves, which affect the activation index, are waveforms that become dominant when performing or attending to relatively simple tasks without physical motion, with minimal activity in the motor or sensory cortices. During the robot programming, the SMR wave was not significantly different between color temperature values $(3000 \mathrm{~K}, 5000 \mathrm{~K}$, and $7000 \mathrm{~K})$. However, the SMR wave magnitude was higher in the presence of LED lighting than in the absence of lighting. The low- $\beta$ wave, generated during learning, is an indicator of learning 
capabilities. It is generated by active mental activities, including learning, memorizing, and calculating. During the robot programming activity, the low- $\beta$ wave was prominent at $7000 \mathrm{~K}$, consistent with results from a subjective evaluation reporting that students show greater activity at higher color temperatures [28].

The activation index at the left and right prefrontal lobes and the right occipital lobe was high at $7000 \mathrm{~K}$. The activation index at the left occipital lobe was slightly higher at $5000 \mathrm{~K}$ than at $7000 \mathrm{~K}$ (Fig 3 and Table VI). However, the average activation index was higher at $7000 \mathrm{~K}$, implying that the brain was highly active at $7000 \mathrm{~K}$ during the robot programming activity. At $7000 \mathrm{~K}$, the increase in EEG activity index was greatest at the left prefrontal lobe, and greater at the prefrontal lobes compared to the occipital lobes.

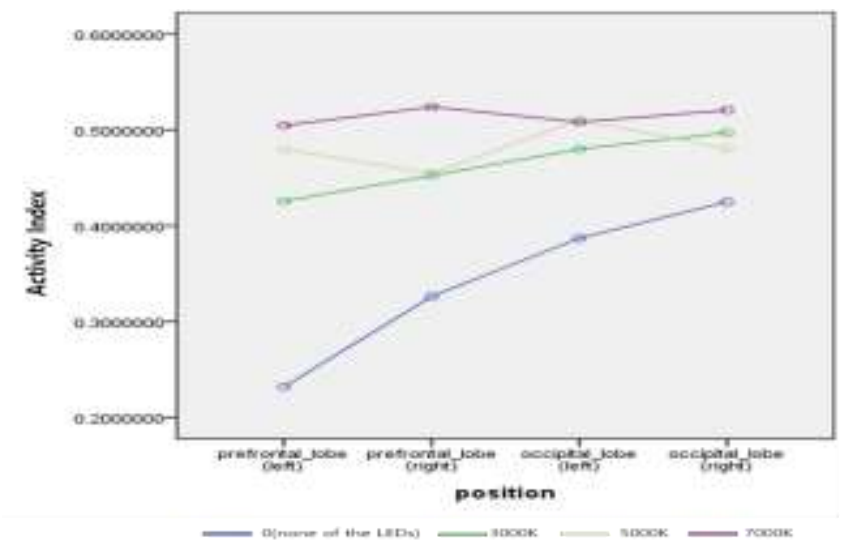

Fig. 3 The activation index at different brain positions during robot pro-gramming under LED lighting

Table VI. Activation indices according to brain positions and color temper-atures

\begin{tabular}{c|c|c|c|c}
\hline \multicolumn{2}{c|}{ Variable } & & SD & N \\
\hline Group & $\begin{array}{c}\text { Color-Temperature } \\
{[\mathrm{K}]}\end{array}$ & $\mathrm{M}$ & .1712390802 & 25 \\
Prefrontal & 0 & .231859983 & .7311343075 & 25 \\
Lobe(left) & 3000 & .425662002 & .7569621350 & 25 \\
& 5000 & .479627586 & .8878689791 & 25 \\
& 7000 & .504558373 & .4365942663 & 25 \\
Prefrontal & 0 & .326370243 & .8631988172 & 25 \\
Lobe(right) & 3000 & .452443693 & .7446792036 & 25 \\
& 5000 & .454750788 & .8791819341 & 25 \\
& 7000 & .524059814 & .2555792618 & 25 \\
Occipital & 0 & .387050516 & .4693890385 & 25 \\
Lobe(left) & 3000 & .479981773 & .46125499440 & 25 \\
& 5000 & .510457141 & .4968973392 & 25 \\
& 7000 & .508172661 & .3799886975 & 25 \\
Occipital & 0 & .425065152 & .4099810533 & 25 \\
Lobe(right) & 3000 & .497164734 & .4074339143 & 25 \\
& 5000 & .480161720 & .4551374602 & 25 \\
\hline
\end{tabular}

In the occipital lobe group, the activation indices were lower at the prefrontal lobes but higher at the occipital lobes compared to those of the prefrontal lobe group. The activation index was high at $7000 \mathrm{~K}$ in both occipital lobe and prefrontal lobe groups. However, the change in activation index from the condition without LED lighting was more drastic in the prefrontal lobe group. The EEG activation index was significantly 
different between the two groups in the absence of LED lighting, but no significant difference was observed at $7000 \mathrm{~K}$. EEG was activated to the same degree at $7000 \mathrm{~K}$ during the robot programming activity regardless of personal characteristics. No significant difference in activation index between different color temperatures were observed $(\mathrm{P}<0.05)$. This suggests that lighting with a color temperature of $7000 \mathrm{~K}$ may have positive effects problem-solving capacity, which is a useful skill for the Fourth Industrial Revolution.

Fig 4 and Table VII show the variation in activation index in the two groups depending on temperature conditions during the robot programming activity.

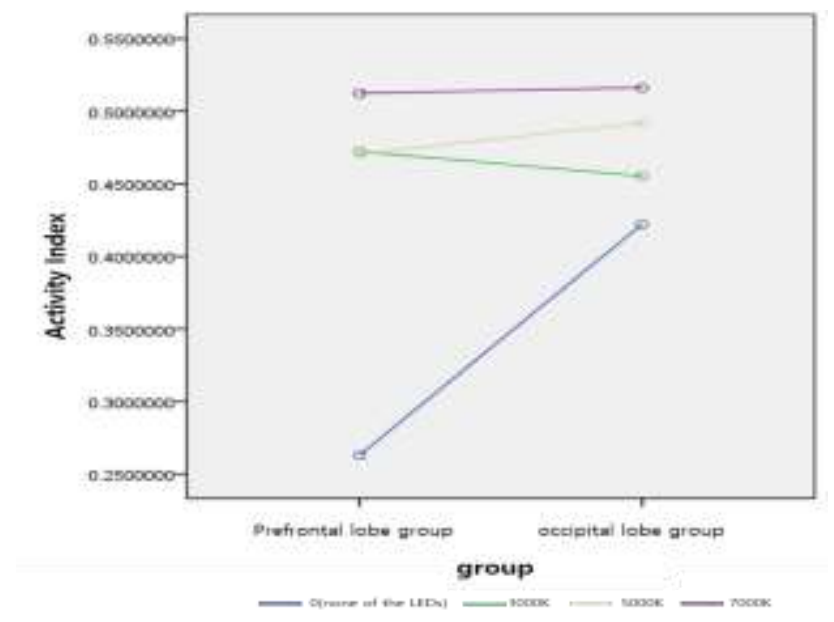

Fig. 4 Activation index for prefrontal and occipital lobe groups during robot programming under LED lighting

Table VII. Activation indices according to groups and color temperatures

\begin{tabular}{c|c|c|c|c}
\hline \multicolumn{2}{c|}{ Variable } & \multirow{2}{*}{ M } & SD & N \\
\cline { 1 - 2 } $\begin{array}{c}\text { Color Temperature } \\
{[\mathrm{K}]}\end{array}$ & Group & & & 52 \\
\hline 0 & Prefrontal group & .262998887 & .3432297133 & 52 \\
0 & Occipital group & .422174060 & .2980030997 & 48 \\
3000 & Prefrontal group & .472292092 & .7971645715 & 52 \\
3000 & Occipital group & .455334009 & .4196577362 & 48 \\
5000 & Prefrontal group & .470349129 & .7575998795 & 52 \\
5000 & Occipital group & .492149489 & .3977812996 & 48 \\
7000 & Prefrontal group & .512412911 & .8820843124 & 52 \\
7000 & Occipital group & .516274661 & .4482535236 & 48 \\
\hline
\end{tabular}

Scheffé's test did not reveal a significant difference in activity between the two groups.

\subsection{CONCENTRATION INDEX DURING ROBOT PROGRAMMING UNDER LED LIGHTING}

The theta $(\theta)$-wave, an EEG wave related to the concentration index, is often generated in an emotionally stable state or during sleep. The $\theta$-wave is related to memory, creativity, concentration, and ataraxia.

The average concentration index was highest at $7000 \mathrm{~K}$ (Fig 5 and Table VIII). The concentration index was higher in the presence of LED lighting than in the absence of lighting, indicating that the concentration index gradually increased with color 
temperature. The highest concentration index was observed at the left and right occipital lobes. Furthermore, the concentration index at the left and right occipital lobes was slightly higher at $5000 \mathrm{~K}$ than at $7000 \mathrm{~K}$. The average concentration index was higher at $7000 \mathrm{~K}$ than in the absence of lighting. The concentration index was higher at the prefrontal lobes than at the occipital lobes.

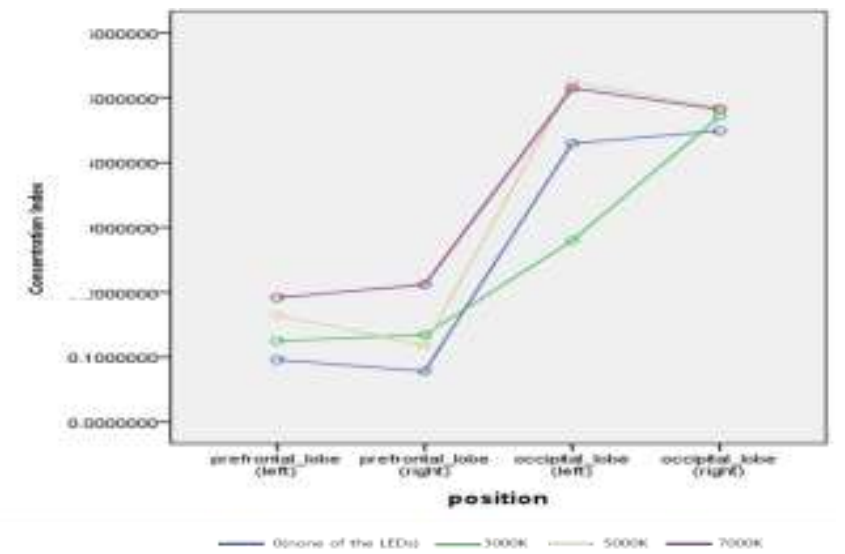

Fig. 5 The concentration indices of brain positions during robot pro-gramming under LED lighting

Table VIII. Concentration indices according to brain positions and color temperatures

\begin{tabular}{c|c|c|c|c}
\hline \multicolumn{2}{c|}{ Variable } & & & \\
Group & $\begin{array}{c}\text { Color Temperature } \\
{[\mathrm{K}]}\end{array}$ & $\mathrm{M}$ & $\mathrm{N}$ \\
\cline { 1 - 2 } Prefrontal & 0 & .092249266 & .1146649089 & 25 \\
Lobe(left) & 3000 & .124704342 & .2319912951 & 25 \\
& 5000 & .164261174 & .2871820953 & 25 \\
& 7000 & .191682529 & .3847319455 & 25 \\
Prefrontal & 0 & .078306389 & .0902950135 & 25 \\
Lobe(right) & 3000 & .134429394 & .2987248134 & 25 \\
& 5000 & .118281066 & .1744095508 & 25 \\
& 7000 & .211949736 & .5148639235 & 25 \\
Occipital & 0 & .429542033 & .1532203362 & 25 \\
Lobe(left) & 3000 & .279609659 & .2974661566 & 25 \\
& 5000 & .524333365 & .3226277604 & 25 \\
& 7000 & .514564759 & .3216563060 & 25 \\
Occipital & 0 & .448832806 & .1740586404 & 25 \\
Lobe(right) & 3000 & .471066978 & .2745916812 & 25 \\
& 5000 & .485002090 & .2925900659 & 25 \\
& 7000 & .482124400 & .2598760144 & 25 \\
\hline
\end{tabular}

The concentration index was higher in the occipital lobe group than in the prefrontal lobe group. The average concentration index was high at $7000 \mathrm{~K}$. In addition, the concentration index was significantly higher at the left and right occipital lobes than at the left and right prefrontal lobes $(\mathrm{P}<0.05)$. Notably, the con-centration index measured at the left occipital lobe was higher at $5000 \mathrm{~K}$ than at $7000 \mathrm{~K}$, which supports the previous result that a color temperature over $5000 \mathrm{~K}$ may facilitate learning in mathematics and sciences [29].

Fig 6 and Table IX show the variation in concentration index depending on three-color temperature conditions during the robot programming activity. 


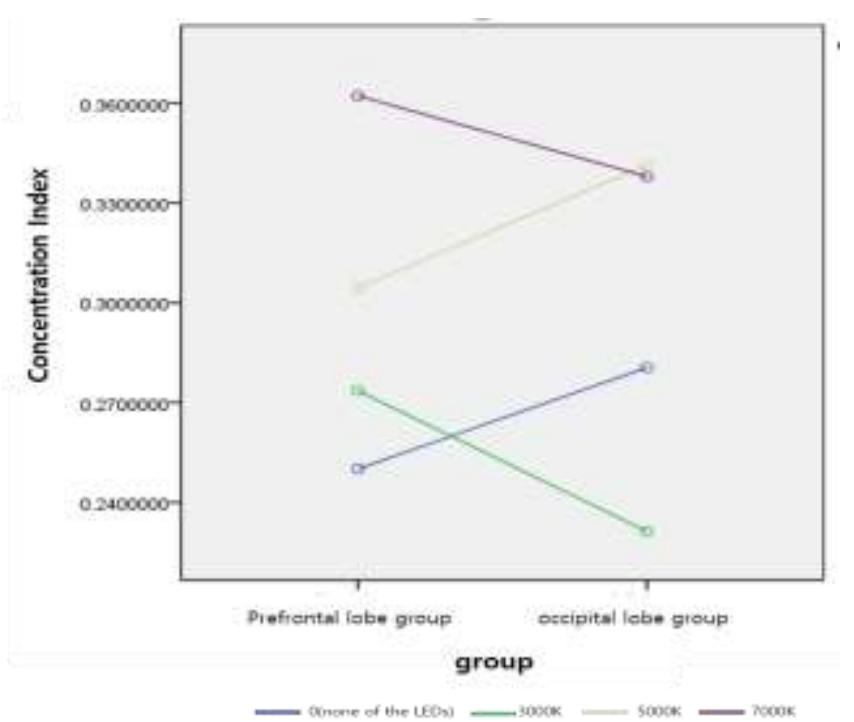

Fig. 6 The concentration indexes of two groups during robot programming under LED lighting.

Table IX. Concentration indices according to groups and color temperatures

\begin{tabular}{c|c|c|c|c}
\hline \multicolumn{2}{c|}{ Variable } & M & SD & N \\
\cline { 1 - 2 }$\left[\begin{array}{c}\text { Color Temperature } \\
{[\mathrm{K}]}\end{array}\right.$ & Group & .250077085 & .1970464290 & 52 \\
\hline 0 & Prefrontal group & .280542705 & .2474961045 & 48 \\
0 & Occipital group & .273602248 & .3151538300 & 52 \\
3000 & Prefrontal group & .231302939 & .2989304444 & 48 \\
3000 & Occipital group & .304505353 & .2559001908 & 52 \\
5000 & Prefrontal group & .341433495 & .3868365229 & 48 \\
5000 & Occipital group & .362216846 & .4330051898 & 52 \\
7000 & Prefrontal group & .337943866 & .3761742135 & 48 \\
7000 & Occipital group & & &
\end{tabular}

There was no statistically significant difference in concentration between the two groups, although there was a difference in the indices of both groups according to color temperatures.

\subsection{STRESS INDEX DURING ROBOT PROGRAMMING UNDER LED LIGHTING}

Light can act as a stressor. Appropriate stress can provide tension and stimulate momentum for activities. Indeed, lack of stress can induce boredom. Therefore, appropriate stress is needed, and coping with stress leads to improvement in individual ability.

The average stress index was highest at $7000 \mathrm{~K}$ (Fig 7 and Table $\mathrm{X}$ ). The average stress index was higher in the presence of lighting than in the absence of lighting, indicating that the concentration index gradually increased with color temperature. The highest stress index was observed at the right prefrontal lobes. In addition, the stress index at the left occipital lobe was slightly higher at $5000 \mathrm{~K}$ than at $7000 \mathrm{~K}$. However, the average concentration index was higher at $7000 \mathrm{~K}$ than in the absence of lighting. The stress index was higher at the prefrontal lobes than at the occipital lobes. 
The prefrontal lobe is active when solving problems that re-quire extensive mental resources. As subjects were solving men-tally-intensive problems when programming robots, the prefrontal lobe was active and provided appropriate tension. The appearance of the stress index at each color temperature indicates that the color temperature is affected by robot programming.

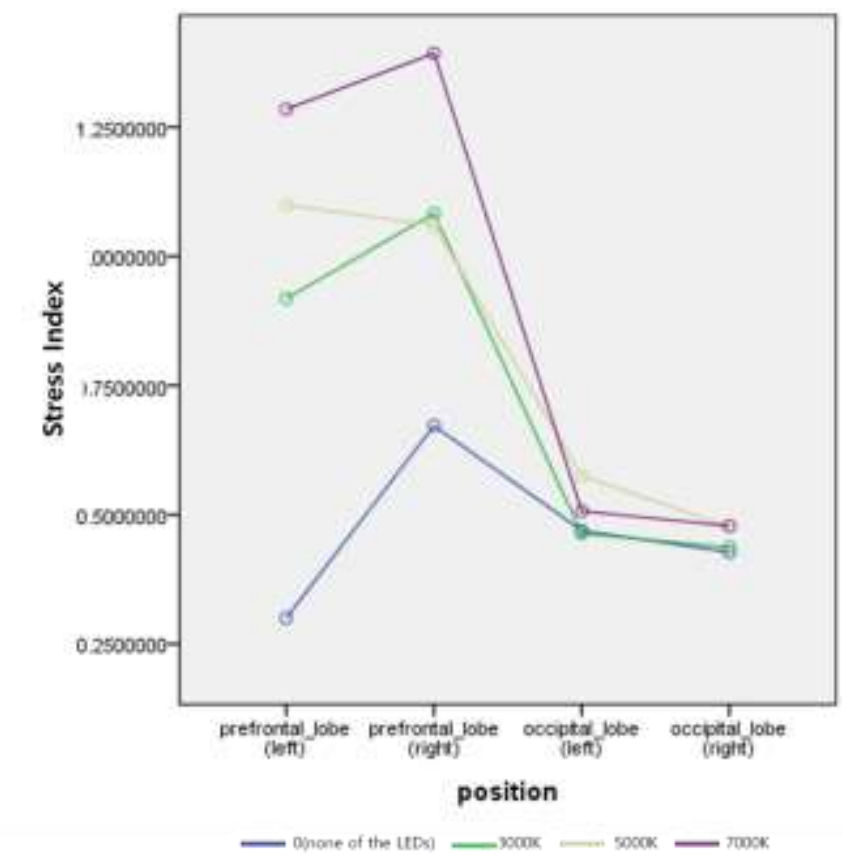

Fig. 7 The stress indices of brain positions during robot programming under LED lighting

Table X. Stress indices according to brain positions and color tempera-tures

\begin{tabular}{c|c|c|c|c}
\hline \multicolumn{2}{c|}{ Variable } & & S & N \\
\hline Group & $\begin{array}{c}\text { Color Temperature } \\
{[\mathrm{K}]}\end{array}$ & & & \\
\hline & 0 & .299956664 & .3255006639 & 25 \\
Prefrontal & 3000 & .918359340 & 2.3467239947 & 25 \\
Lobe(left) & 5000 & 1.099466529 & 2.6612224983 & 25 \\
& 7000 & 1.284659237 & 3.6884425270 & 25 \\
& 0 & .672264710 & 1.5984261409 & 25 \\
Prefrontal & 3000 & 1.083123617 & 3.1678320457 & 25 \\
lobe (right) & 5000 & 1.060502614 & 2.9893624225 & 25 \\
& 7000 & 1.393040919 & 3.9483001006 & 25 \\
& 0 & .469300740 & .3173600781 & 25 \\
Occipital & 3000 & .463613706 & .3570951388 & 25 \\
lobe (left) & 5000 & .575447376 & .4838599701 & 25 \\
& 7000 & .506860455 & .3277310066 & 25 \\
& 0 & .467152419 & .8448279357 & 25 \\
Occipital & 3000 & .725540076 & 1.9632135694 & 25 \\
lobe (right) & 5000 & .802998342 & 1.9989879881 & 25 \\
& 7000 & .915707468 & 2.6872644190 & 25 \\
\hline
\end{tabular}


The stress indices of both groups were significantly different $(\mathrm{P}<0.05)$. The stress index was higher in the occipital lobe group than in the prefrontal lobe group, and the average stress index was high at $7000 \mathrm{~K}$ (Fig 8 and Table XI). The stress index of the occipital lobe group was higher at $5000 \mathrm{~K}$ than at $7000 \mathrm{~K}$.

Fig 8 shows variations in the stress index depending on three-color temperature conditions during the robot programming activity.

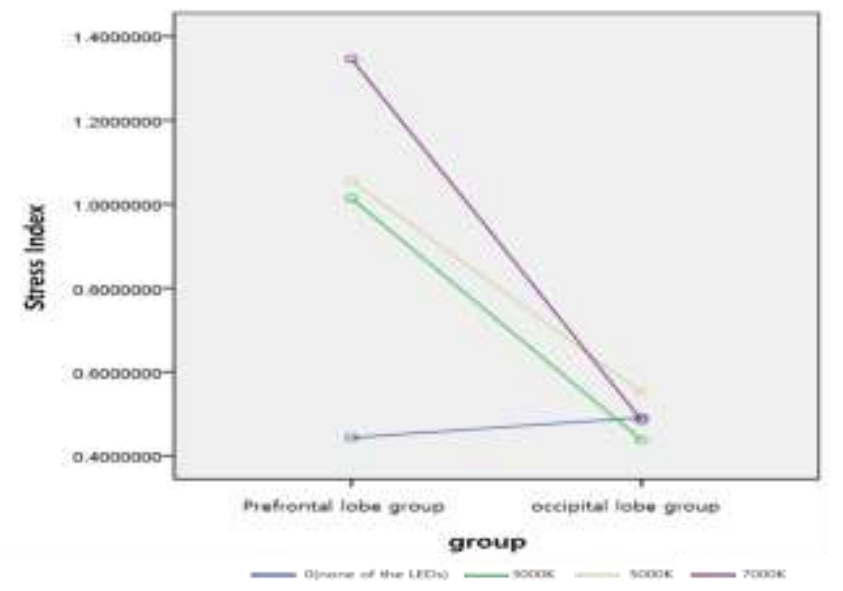

Fig. 8: The stress indices of prefrontal and occipital lobe groups during robot programming under LED lighting

Table XI. Stress index according to groups and color temperatures

\begin{tabular}{c|c|c|c|c}
\hline \multicolumn{2}{c|}{ Variable } & \multirow{2}{*}{ M } & SD & N \\
\cline { 1 - 2 } $\begin{array}{c}\text { Color Temperature } \\
{[\mathrm{K}]}\end{array}$ & Group & .443027919 & 1.1592213543 & 52 \\
\hline 0 & Prefrontal group & .491276918 & .3207327560 & 48 \\
0 & Occipital group & 1.013781777 & 2.7516835156 & 52 \\
3000 & Prefrontal group & .437298375 & .2754249628 & 48 \\
3000 & Occipital group & 1.055379933 & 2.8049489129 & 52 \\
5000 & Prefrontal group & .550616750 & .3275742664 & 48 \\
5000 & Occipital group & 1.346329349 & 3.7688554488 & 52 \\
7000 & Prefrontal group & .485085588 & .2517289141 & 48 \\
7000 & Occipital group & & & \\
\hline
\end{tabular}

\section{Conclusion}

The present study was conducted to analyze the effects of LED lighting with three different color temperature values on stability, concentration, activation, and stress indices of EEG during a robot programming activity. EEG was measured during a robot programming activity either in the absence or presence of LED lighting with different color temperatures. The following conclusions were obtained from the analysis of the measured EEG data.

First, the stability index, represented by the $\alpha$-wave, was higher at higher color temperatures. The balance of the $\alpha$-wave between the left and right brain was best at 5000 $\mathrm{K}$ in the occipital lobe. Superior performance may be achieved when individuals feel at ease and achieve harmony between body and mind. Balance of the $\alpha$-wave between the left and right brain is important, because the $\alpha$-wave is an objective indicator of stability. Therefore, our results suggest that lighting of $5000 \mathrm{~K}$ may be recommended for a 
subpopulation of students performing a robot programming activity. Stability and stress indices showed the opposite results. In other words, we recommend installing LED lighting with $5000 \mathrm{~K}$ color temperature in the classrooms for robot programming activities because the stability is high and the stress is low at $5000 \mathrm{~K}$ color temperatures.

Second, the activation index during the robot programming activity was high at 7000 $\mathrm{K}$, suggesting that this LED lighting may facilitate performance. A previous study showed that the appropriate color temperature for relaxation of the body and mind (for example, in meditation) was as low as $3000 \mathrm{~K}$, but the brain was highly activated at 4142 $\mathrm{K}$ or $6850 \mathrm{~K}$. The results of the present study also support previous results, indicating that high color temperature promoted brain activity during the robot programming activity.

Third, the concentration index was high at $7000 \mathrm{~K}$, especially at the occipital lobes. Comparison of the concentration index between the prefrontal lobe and occipital lobe groups revealed a high concentration index at $5000 \mathrm{~K}$ in the occipital lobe group. While a high concentration index is needed for high performance, our results demonstrated a high concentration index at $5000 \mathrm{~K}$ and $7000 \mathrm{~K}$. This is consistent with a previous finding that high color temperature improved learning in mathematics. The results of the present study revealed that a high color temperature of $7000 \mathrm{~K}$ was beneficial for the robot programming activity and that some students showed a high degree of con-centration even at the color temperature of $5000 \mathrm{~K}$. The present study also demonstrated that the occipital lobes were affected by LED lighting. High color temperature during the robot programming activity affected the left hemisphere, which is involved in solving problems logically and analytically more than right hemisphere [30-32].

Fourth, the stress index was high at $7000 \mathrm{~K}$ in most regions but high at $5000 \mathrm{~K}$ only in the left occipital lobe. In the prefrontal lobe group, the stress index was high at $7000 \mathrm{~K}$; in the occipital lobe group, it was high at 5000K. Most people are positively affected in work or learning when they are optimally stressed; according to our results, these positive effects are seen at $5000 \mathrm{~K}$ or $7000 \mathrm{~K}$.

Given that the $\alpha$-wave is generated from different parts of the brain in different people implies that personal characteristics differ between individuals. The present study revealed that EEG was dependent on the regions from which an $\alpha$-wave was generated, indicating that the effect of LED lighting is dependent on personal characteristics. In addition, the activation and concentration indices were different between the left and right brain. Since the overall stability, activation, and concentration index were increased by the high color temperature of $7000 \mathrm{~K}$ in the robot programming activity, we propose that the high color temperature of $7000 \mathrm{~K}$ should be applied in educational software and activities to improve computing-based thinking and problem-solving.

Several subjects were affected by the color temperature of $5000 \mathrm{~K}$, indicating that LED lighting of various color temperature values are dependent on individual characteristics and types of educational activities. Therefore, LED lighting of various color temperature values may be appropriately installed in educational facilities where individuals with different personal characteristics gather to perform various types of activities.

Further studies are needed to investigate the effects of LED lighting on the variations in EEG depending on personal characteristics in various types of educational activities other than robot programming.

\section{ACKNOWLEDGEMENTS}

This study was supported by the Korea Research Institute of Chemical Technology, Korea Photonics Technology Institute and Millennium Light Rims Co., Ltd.

\section{REFERENCES}

[1] Jee SD, Kim CB, "Electroencephalogram Analysis on Learning Factors During Relaxed or Concentrated Attention According to the Color Temperatures of LED lighting". Journal of the Korea Insitute Education Facilities, Vol. 21, (2014), pp. 33-42. 
[2] Jee SD, Kim CB, "Evaluation of Concentration and Visual Discrimination According to the Color Temperatures of LED Illumination". The Journal of Korean Institute of Educational Facilities, Vol. 18, (2011), pp. 23-33.

[3] Lee HJ, Choi YR, \& Chun CY, "Effect of Indoor Air Temperature on the Occupants' Attention Ability based on the Electroencephalogram Analysis". Architectural Institute of Korea, Vol. 28, No. 3, (2012), pp. 217-225.

[4] Moon SY, "A Study on an Educational Design Assessment for Computational Thinking Utilizing Brainwave Analysis". Un-published master's thesis of ANDONG University, (2017)

[5] Cheo EJ, "Electroencephalogram Changes in Depression". Journal of the Korea Society of Biological Therapies in Psychiatry, Vol.19, No. 2, (2013), pp. 93-100.

[6] Jung KH, Lee JS, \& Lee JH, "Power Spectral Analysis EEG Characteristics of Major Depressive Disorder". Korea Journal of Clinical Psychology, Vol. 27, No. 3, (2008), pp. 581-593.

[7] Park JS, Lee MK, "Effect of Regular Neurofeedback Training On Attention Span, Neural Reflex, Gross Motor and Fine Motor Function". Asia-pacific Journal of Multimedia Services Convergent with Art, Humanities, and Sociology, Vol. 7, No. 6, (2017), pp. 493-501.

[8] Choi YH, "Analysis of Electroencephalogram (EEG) Activities of Middle School Students in Technological Problem Solving Thinking Process as Levels of Structured Problem". Journal of Korean Practical Arts Education, Vol. 17, No. 4, (2011), pp. 129-152.

[9] Kim KT, Oh SY, Yu M, Yu CH, \& Kwon TK, "Study on Human Physiological Responses to Emotional Lighting System using LED Flat Lighting". Korean Journal of the Science of Emotion \& Sensibility, Vol. 17, No. 3, (2014), pp. 29-38.

[10] Kim SY, Baek YG, "Influence of Color Temperature of Lighting Lamps on Visual Responses in a Small Office". Journal of The Society of Living Environment System, Vol. 16, No. 6, (2009), pp. 630638.

[11] Chio YR, Chun CY, "The effect of indoor temperature on occu-pants' attention abilities". Proceeding of Spring/Autumn Annual Conference of Korean Housing Association, Vol. 25, (2009), pp. 199-203.

[12] Kim SA, Kim CH, \& Jee SD, "Changes of Electroencephalogram (EEG) During Robot Programming Activity in the LED lighting System With Three-Type Color". Proceedings of Asia-Pacific Journal of Advanced Research in Electrical and Electronics Engineering, Vol. 2, No 1, (2018), pp. 1-6.

[13] Kim SA, Yi SB, "Development of Robot Hands-on Activity for Achievement Standards of "Advanced Technology" in "Technology System" Domain Under the 2015 Revised High School "Technology \& Home Economics" Subject Curriculum". The Journal of Learner-Centered Curriculum and Instruction, Vol. 17, No. 7, (2017), pp. 529-548.

[14] Chae JH, Bae YK, \& You IH, "Effects of Robotic Programming Education on the Growth of Logical Thinking Abilities for Elementary Students". Korean Journal of Teacher Education, Vol. 24, No. 2, (2008), pp. 361-376.

[15] Kim SA, Chung DY, "A Study on the Ways of Robotics Programs at Technology Education in Middle School". The Korean Journal of Technology Education, Vol. 6, No. 3, (2006), pp. 127-147.

[16] Sklar E, Parsons S, \& Azhar, MQ, "Robotics Across the Curriculum", Proceedings of AAAI Spring Symposium: Semantic Scientific Knowledge Integration, (2007), pp. 142-147.

[17] Fagin B, Merkle L, "Measuring the Effectiveness of Robots in Teaching Computer Science". Proceedings of ACM SIGCSE Bulletin, Vol. 35, No. 1, (2003), pp. 307-311.

[18] Mataric MJ, Koenig NP, \& Feil-Seifer, D, "Materials for Enabling Hands-On Robotics and STEM Education". Proceedings of AAAI Spring Symposium: Semantic Scientific Knowledge Integration, (2007), pp. 99-102.

[19] Hamner E, Cross J, “Arts \& Bots: Techniques For Distributing a STEAM Robotics Program Through K-12 Classrooms". Proceedings of Integrated STEM Education Conference (ISEC), (2013), pp. 1-5.

[20] Kim SA, Jee SD, "A Survey on Teacher's Cognition for the Improvement of Robotics Education in Public Education", The Journal of Korea Robotics Society, Vol. 6, No. 4, (2011), pp. 365-372.

[21] BBC (2013. 7. 8), 'Curriculum changes to catch up with world's best', Retrieved March 30, 2015, from http://www.bbc.com/news/education-23222068.

[22] Department for Education, The National Curriculum in England Framework document. Department for Education in UK, (2014).

[23] Robotics education in China, Science times, (2018. 6. 4), available online: http://www.sciencetimes.co.kr/?news=\%E4\%B8\%AD-\%EB\%A1\%9C\%EB\%B4\%87$\%$ ЕA\%B $\% 90 \%$ EC $\%$ C \%A1-\%ED\%95\%99\%ЕC\%9B\%90-\%ЕC\%97\%B4\%ED\%92\%8D

[24] Ministry of Education, 2015 Revised National Curriculum, Minis-try of Education in KOREA. (2015).

[25] Research and Markets, Global Educational Robots Market 2018-2022, Research and Markets Report, (2018), pp. 1-111.

[26] Jang HG, "Therapeutic Application of Meditation to the Stress-Related Disorders", Journal of Korean Psychological Association, Vol. 9, No. 2, (2004), pp. 471-492.

[27] Kim WS, Jin SH, "LORETA analysis of EEG responding to positive/negative emotional stimuli for different sensitivities of behavioral activation and inhibition systems", Korean Journal of the Science of Emotion \& Sensibility, Vol. 8, No. 4, pp. 403-413. 
[28] Jee SD, Choi KJ, Kim HK, \& Lee SH, "Sensibility Evaluation of Color Temperature and Rendering Index to the LED-Based White Illumination", Korean Journal of the Science of Emotion \& Sensi-bility, Vol. 9, No. 4, (2006), pp. 353-366.

[29] Oh SK, Im SJ, Ma CM, \& Kim JY, "Development of RGBW Dimming Control Sensitivity Lighting System based on the Intelligence Algorithm", Journal of The Korean Institute of Intelligent Systems, Vol. 21, No. 3, (2011), pp.359-364.

[30] Sperry RW, "Left-brain, right-brain”, Saturday Review, Vol. 2, No. 23, (1975), pp. 30-32.

[31] Mac Neilage PF, Lesley JR, \& Giorgio V, "Origins of the left \& right brain", Scientific American, Vol. 301, No, 1, (2009), pp. 60-67.

[32] Laccino, JF, "Left brain - right brain differences: Inquiries, evidence, and new approaches", Psychology Press, (2014) 